\title{
Development of an Evacuation Device that Enables Persons in Wheelchairs to Descend Stairs
}

\author{
Tomoya Miyasaka, Keiko Kawashima, Mamiko Kamoshida, Katsuyuki Toide, Noriyuki \\ Sugawara, Shinya Hashimoto, Atsushi Matoba, Kouhei Takatsuka, \\ Kenji Edazawa, Masanori Kawai
}

\begin{abstract}
Many residents of elderly facilities such as dementia group homes and special elderly nursing homes require evacuation with assistance during a fire, and the number of caregivers is often limited. The purpose of this study is to develop an evacuation device that enables evacuation using the stairs for wheelchair users living on the second and higher floors in elderly facilities and welfare facilities with assistance by just one caregiver and without the use of an electric motor. The developed machine was provided with a structure that includes a carriage that supports driving, braking, overall load, and a backrest frame that holds and fixes the wheelchair and is operated by a caregiver. A staircase descent experiment was conducted and the results showed that the total operation time was 92.18 seconds on average, which almost achieved the target time of 90 seconds. The result of a questionnaire survey showed that respondents had positive opinions on the necessity of equipment that can evacuate persons in wheelchairs by descending stairs and some said they need to introduce such equipment into their facilities. The lock of the developed machine was improved, which reduced the wheelchair mounting process time by an average of 9.88 seconds. The total operation time was 49.42 seconds on average, which made it possible for the evacuation time to be conducted in under one minute. Further improvements will be carried out leading to greater practical use.
\end{abstract}

Index Terms - Elderly facility, Evacuation, Wheelchair use, Stair descent

\section{INTRODUCTION}

Many residents of elderly facilities such as dementia group homes and special elderly nursing homes require evacuation with assistance during a fire, and the number of caregivers is often limited [1]. A survey of a group home fire evacuation procedures for elderly people with dementia in March 2010 [2] brought to our attention the idea that if there is a means to evacuate downstairs quickly with little assistance, especially

This work was supported by Promotion Program for Scientific Fire and Disaster Prevention Technologies at 2016, 2017.

Tomoya Miyasaka, Department of Physical Therapy, Faculty of Health Sciences, Hokkaido University of Science, Sapporo, Hokkaido, Japan.

Keiko Kawashima, Department of Physical Therapy, Faculty of Health Sciences, Hokkaido University of Science, Sapporo, Hokkaido, Japan.

Mamiko Kamoshida, Department of Physical Therapy, Faculty of Health Sciences, Hokkaido University of Science, Sapporo, Hokkaido, Japan.

Katsuyuki Toide, Sapporo Fire Bureau, Sapporo, Hokkaido, Japan. Noriyuki Sugawara, Sapporo Fire Bureau, Sapporo, Hokkaido, Japan. Shinya Hashimoto, Sapporo Fire Bureau, Sapporo, Hokkaido, Japan. Atsushi Matoba, Sapporo Fire Bureau, Sapporo, Hokkaido, Japan.

Kouhei Takatsuka, Sapporo Fire Bureau, Sapporo, Hokkaido, Japan.

Kenji Edazawa, Sanwa Ltd., Shibuya-ku, Tokyo, Japan.

Masanori Kawai, Sanwa Ltd., Shibuya-ku, Tokyo, Japan. for residents on the upper floors living in a wheelchair, the possibility of evacuation for such residents could be expanded. We therefore made a prototype of a device that can lower a resident in a wheelchair downstairs with the assistance of just one caregiver (Fig. 1) [3].

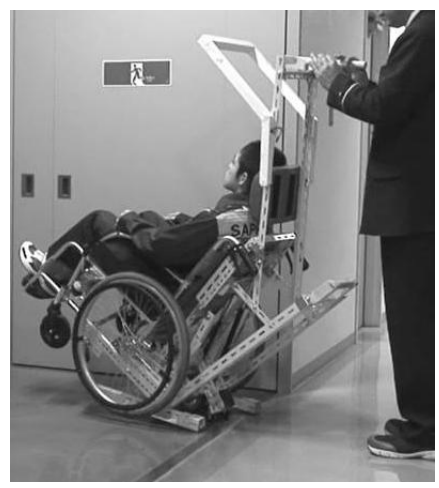

Fig. 1 Preliminary prototype

We also surveyed fire evacuation drills at dementia group homes in 5 cities from 2014 to 2015 . According to the survey results, out of 66 residents in the 5 facilities, there were 19 people who lived on the second or an upper floor of the facilities and used wheelchairs with assistance by caregivers needed for daily transfer and movement, which accounted for $29 \%$ of the total [4]. These findings suggested to us that a device designed to assist the evacuation of persons in wheelchairs downstairs would be one of the more effective evacuation means for those who live in wheelchairs upstairs. The purpose of this study is to develop an evacuation device that enables evacuation using the stairs for wheelchair users living on the second and higher floors in elderly facilities and welfare facilities with assistance by just one caregiver and without the use of an electric motor.

\section{METHOD}

\section{A. Specifications and configuration of developed machine}

Table. 1 shows the specifications of the developed machine. We made use of the configuration of a conventional stair evacuation vehicle [5] in development of the machine for good functionality and performance including operational reliability, safety and robustness. The machine was also equipped with a folding mechanism for easy storage. A safety consideration was given to the brake mechanism so that the device would not run on its own even if the operator releases his hand while descending the stairs. A standard manual 
wheelchair [6] was used to install the device for general use.

Table 1 The specifications of the developed machine

\begin{tabular}{|lc|}
\hline Total height of vehicle (when stored) $(\mathrm{mm})$ & $901(300)$ \\
Total length of vehicle (when stored) $(\mathrm{mm})$ & $1451(1276)$ \\
Full body width (when stored) $(\mathrm{mm})$ & $606(606)$ \\
Weight $(\mathrm{kg})$ & 24 \\
Maximum loading capacity $(\mathrm{kg})$ & 135 \\
Descent angle $\left(^{\circ}\right)$ (maximum) & 35 \\
Brake on the floor & Available \\
Brake on stairs & Available \\
Folding mechanism during storage & Available \\
Wheelchair used for device installation & Standard manual \\
& wheelchair \\
\hline
\end{tabular}

The developed machine was provided with a structure that includes a carriage that supports driving, braking, overall load, and a backrest frame that holds and fixes the wheelchair and is operated by a caregiver. The backrest frame section can be folded and stored. The stored state is shown in Fig. 2, and the upright state is shown in Fig. 3.

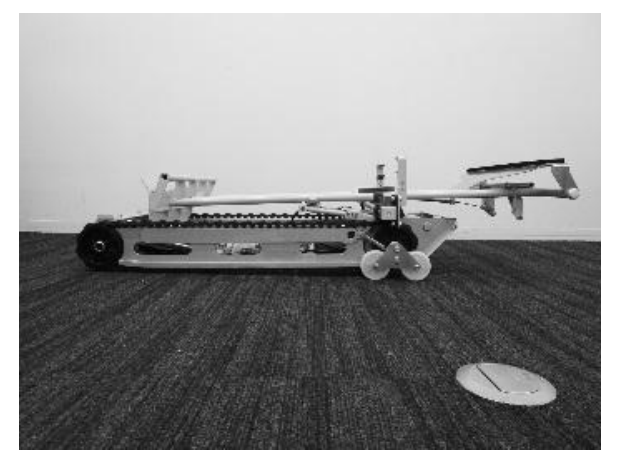

Fig. 2 Developed machine (with backrest frame folded)

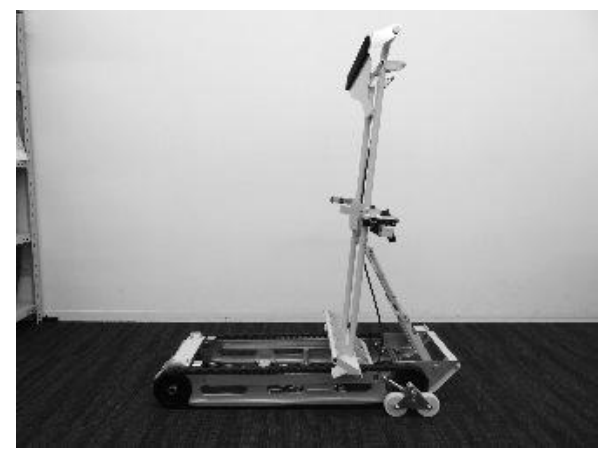

Fig. 3 Developed machine (with backrest frame standing upright)

Fig. 4 shows a state where a standard wheelchair is mounted on the developed machine, and Fig. 5 shows a state where the mounted wheelchair is tilted backward. The wheelchair was mounted on the developed machine with the tipping lever of the wheelchair placed on the wheelchair cradle at the bottom of the backrest frame of the developed machine, and the upper backrest of the wheelchair was fixed with the left and right clamps on the backrest frame of the machine (Fig. 6).

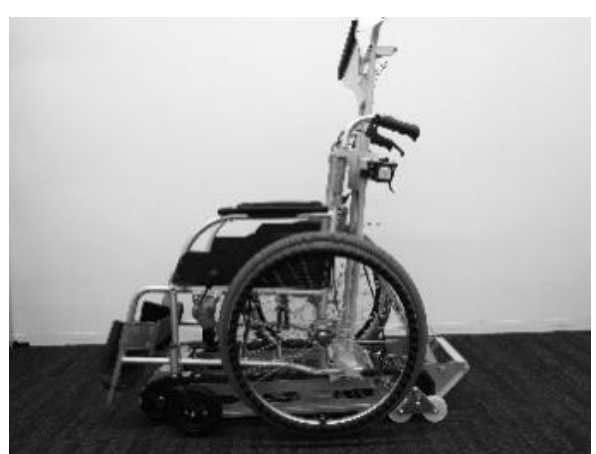

Fig. 4 Mounting a wheelchair

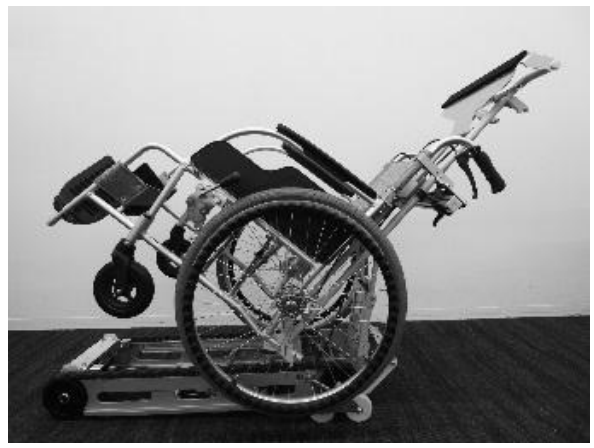

Fig. 5 Mounting a wheelchair (tilting the wheelchair backward)

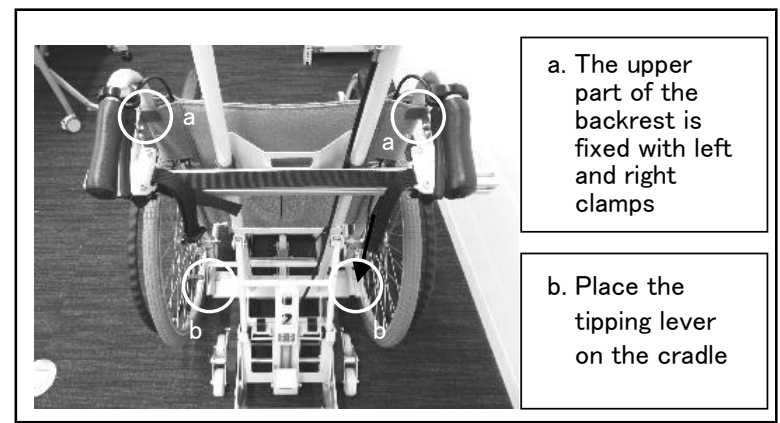

Fig. 6 Fixing the wheelchair

\section{B. Operation of the developed machine}

Operation of the developed machine was as follows: Raising the back frame (Fig. 7), Mounting the wheelchair (Fig. 8), Moving on the upper floor (Fig. 9), Descending the stairs (Fig. 10), Moving on the lower floor (Fig. 11), Removing the wheelchair (Fig. 12) ), and we confirmed that it was able to be operated by just one caregiver.

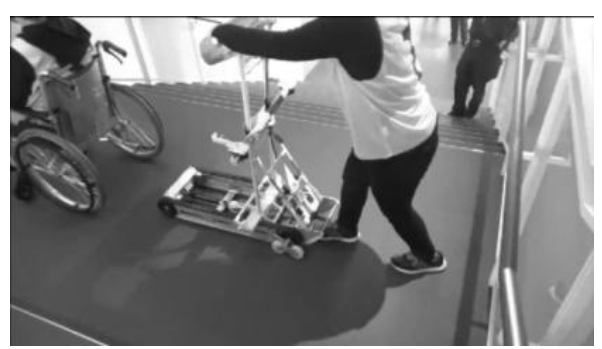

Fig. 7 Raising the back frame 


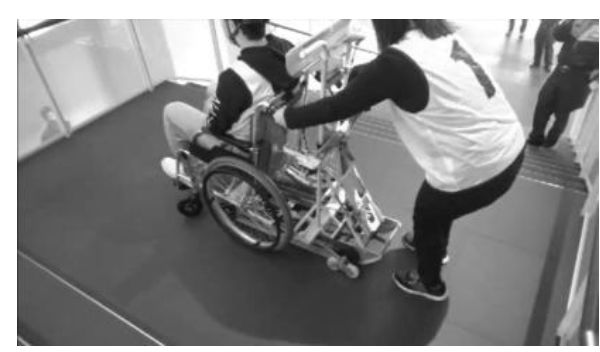

Fig. 8 Mounting the wheelchair

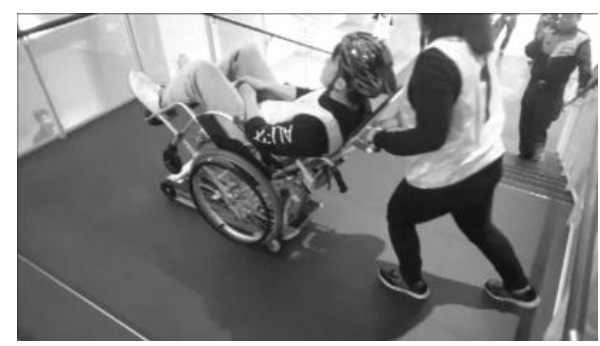

Fig. 9 Moving on the upper floor

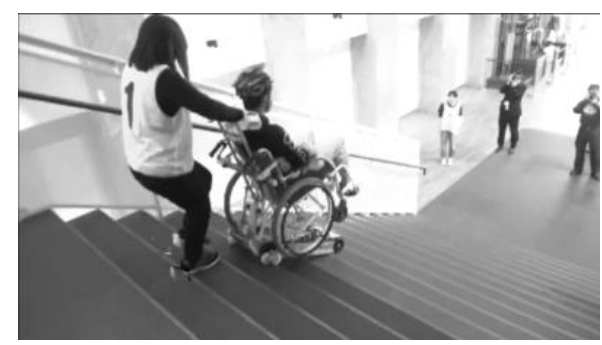

Fig. 10 Descending the stairs

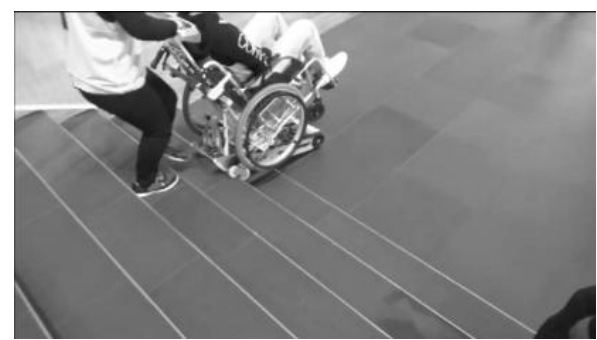

Fig. 11 Moving on the lower floor

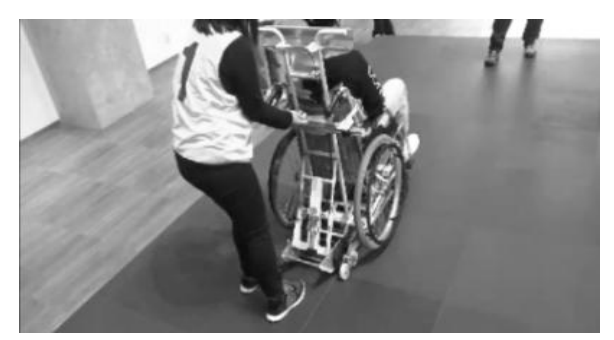

Fig. 12 Removing the wheelchair

\section{Evaluation of the developed machine}

We conducted two evaluations on the developed machine: a descending stairs experiment that measures the time of the operation process at the university campus, and a questionnaire survey with a trial of the machine at an elderly facility. Before conducting the research, we explained the research to the participants and obtained their informed consent pursuant to the research ethics application number
266 of Hokkaido University of Science. Experiments and trials were conducted with due consideration for the safety of the participants.

Stair descent experiments (Fig. 13) were carried out with a total of 9 participants consisting of 6 university students (participant group A) over 20 years old, and 3 fire fighters (participant group B) who operated the developed machine to descend the stairs. The participants performed 18 trials in total, with one participant operating the machine twice while another participant used the wheelchair in turns. The staircase had an inclination angle of $27^{\circ}$ and 17 steps, and experiments were carried out through five phases including "Mounting the wheelchair", "Moving on the upper floor", "Descending the stairs", "Moving on the lower floor", and "Removing the wheelchair". The operation process was videoed and the time for each phase was totaled. The target time for the operation process was set to 90 seconds.

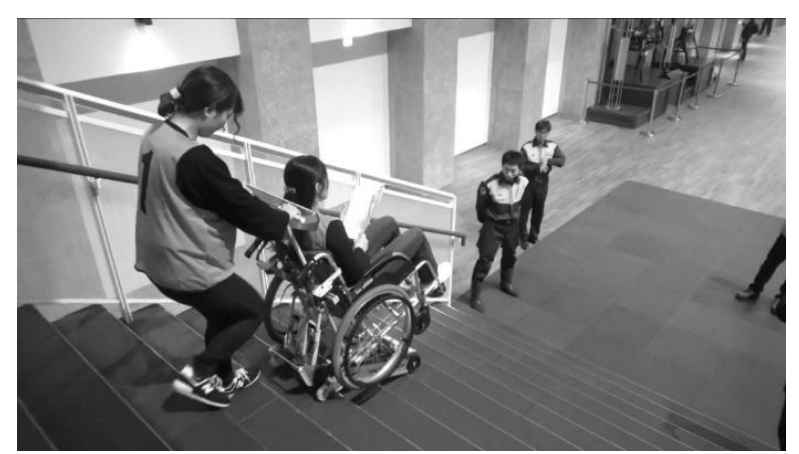

Fig. 13 Stair descent experiment

The questionnaire survey with trials was carried out by bringing the developed machine into 2 elderly facilities (1 special nursing home for the elderly (Fig. 14) and 1 dementia group home (Fig. 15)), and the facility staff ( 3 persons per facility, 6 persons in total) were asked to try out the developed machine, and a descriptive questionnaire survey was then conducted.

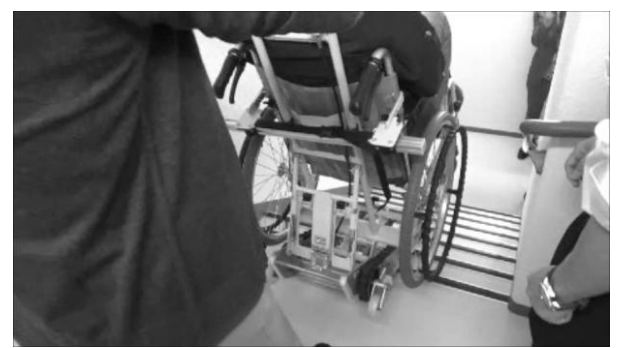

Fig. 14 Trial at a special elderly nursing home

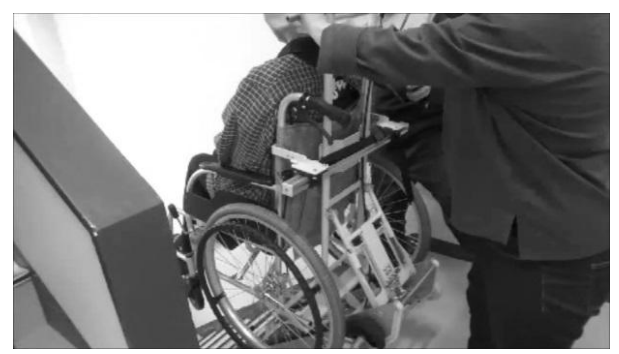

Fig. 15 Trial at a dementia group home 


\section{RESULTS}

\section{A. Results of stair descent experiment}

The results of the calculation of the operation process times are shown in Table 2. The total operation process time for the two groups was 92.18 seconds on average. Of each process, the "Mounting the wheelchair" process time was 43.74 seconds on average for the two groups, accounting for $47.5 \%$ of the total operation process.

Table 2 Operation process time

\begin{tabular}{|c|c|c|c|c|c|c|c|}
\hline & $\begin{array}{c}\text { Number of } \\
\text { process }\end{array}$ & 1 & 2 & 3 & 4 & 5 & \\
\hline & Operation & $\begin{array}{c}\text { Mounting } \\
\text { the } \\
\text { wheelchai }\end{array}$ & $\begin{array}{l}\text { Moving } \\
\text { on the } \\
\text { upper }\end{array}$ & $\begin{array}{l}\text { Descend- } \\
\text { ing the } \\
\text { stairs }\end{array}$ & $\begin{array}{l}\text { Moving } \\
\text { on the } \\
\text { lower }\end{array}$ & $\begin{array}{c}\text { Removing } \\
\text { the } \\
\text { wheelchai }\end{array}$ & Total \\
\hline \multirow{5}{*}{$\begin{array}{c}\text { Participant } \\
\text { group A }\end{array}$} & Average (s) & 50.20 & 9.88 & 20.49 & 3.09 & 17.91 & 101.56 \\
\hline & \begin{tabular}{|l|} 
Minimum (s) \\
\end{tabular} & 33.63 & 5.33 & 14.40 & 2.47 & 14.03 & 76.57 \\
\hline & \begin{tabular}{|l} 
Maximum (s) \\
\end{tabular} & 100.93 & 14.53 & 28.10 & 4.90 & 28.30 & 151.10 \\
\hline & \begin{tabular}{|l|} 
Standard \\
deviation (s)
\end{tabular} & 20.08 & 2.73 & 4.12 & 0.70 & 4.74 & 23.41 \\
\hline & $\begin{array}{l}\text { Coefficient of } \\
\text { variation }\end{array}$ & 0.40 & 0.28 & 0.20 & 0.23 & 0.26 & 0.23 \\
\hline \multirow{5}{*}{$\begin{array}{c}\text { Participant } \\
\text { group B }\end{array}$} & Average (s) & 30.84 & 6.68 & 15.75 & 3.35 & 16.77 & 73.40 \\
\hline & Minimum (s) & 22.70 & 3.80 & 12.00 & 2.03 & 11.87 & 65.37 \\
\hline & Maximum (s) & 35.93 & 12.47 & 20.17 & 4.63 & 20.13 & 87.77 \\
\hline & \begin{tabular}{|l|} 
Standard \\
deviation (s)
\end{tabular} & 4.84 & 3.45 & 3.16 & 0.99 & 3.11 & 7.53 \\
\hline & \begin{tabular}{|l}
$\begin{array}{l}\text { Coefficient of } \\
\text { variation }\end{array}$ \\
\end{tabular} & 0.16 & 0.52 & 0.20 & 0.30 & 0.19 & 0.10 \\
\hline \multirow{5}{*}{$\begin{array}{c}\text { Total of A } \\
\text { and B }\end{array}$} & Average (s) & (43.74 & 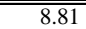 & | 18.91 & 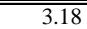 & $\overline{c 17.53}$ & 92.18 \\
\hline & Minimum (s) & 22.70 & 3.80 & 12.00 & 2.03 & 11.87 & 65.37 \\
\hline & \begin{tabular}{|l|} 
Maximum (s) \\
\end{tabular} & 100.93 & 14.53 & 28.10 & 4.90 & 28.30 & 151.10 \\
\hline & $\begin{array}{l}\text { Standard } \\
\text { deviation (s) }\end{array}$ & 18.87 & 3.28 & 4.38 & 0.79 & 4.21 & 23.62 \\
\hline & $\begin{array}{l}\text { Coefficient of } \\
\text { variation }\end{array}$ & 0.43 & 0.37 & 0.23 & 0.25 & 0.24 & 0.26 \\
\hline
\end{tabular}

Table 3 Subjective evaluation of operation processes

\begin{tabular}{|c|c|c|c|c|c|c|}
\hline \multicolumn{2}{|c|}{ Number of process } & 1 & 2 & 3 & 4 & 5 \\
\hline \multicolumn{2}{|c|}{$\begin{array}{c}7 \text { grades: } 7 \text { is the best } \\
\text { Median values shown in the } \\
\text { table }\end{array}$} & $\begin{array}{c}\begin{array}{c}\text { Mounting } \\
\text { the } \\
\text { wheelchair }\end{array}\end{array}$ & $\begin{array}{l}\text { Moving on } \\
\text { the } \\
\text { upper floor }\end{array}$ & $\begin{array}{l}\text { Descend- } \\
\text { ing the } \\
\text { stairs }\end{array}$ & $\begin{array}{l}\text { Moving } \\
\text { on the } \\
\text { lower } \\
\text { floor }\end{array}$ & $\begin{array}{c}\text { Removing } \\
\text { the } \\
\text { wheelchair }\end{array}$ \\
\hline Participant group A & \multirow{3}{*}{$\begin{array}{l}\text { Operation } \\
\text { force }\end{array}$} & 5 & 6 & 6 & 4.5 & 6 \\
\hline Participant group B & & 4 & 7 & 7 & 3 & 4 \\
\hline $\begin{array}{l}\text { Participant group } \\
\text { A and B }\end{array}$ & & 4 & 6 & 6 & 4 & 6 \\
\hline Participant group A & \multirow{3}{*}{$\begin{array}{c}\text { Easiness of } \\
\text { operation }\end{array}$} & 5 & 6 & 6 & 4.5 & 6 \\
\hline Participant group B & & 4 & 6 & 6 & 3.5 & 4 \\
\hline $\begin{array}{l}\text { Participant group } \\
\mathrm{A} \text { and B }\end{array}$ & & 5 & 6 & 6 & 4 & 5.5 \\
\hline \begin{tabular}{|l|} 
Participant group A \\
\end{tabular} & \multirow{3}{*}{$\begin{array}{c}\text { Comfort } \\
\text { level when } \\
\text { using the } \\
\text { wheelchair }\end{array}$} & 6 & 5 & 6 & 5.5 & 6 \\
\hline Participant group B & & 4 & 4 & 3.5 & 3.5 & 4 \\
\hline $\begin{array}{l}\text { Participant group } \\
\text { A and B }\end{array}$ & & 5.5 & 5 & 5 & 5 & 6 \\
\hline Participant group A & \multirow{3}{*}{$\begin{array}{c}\text { Sense of } \\
\text { ease when } \\
\text { using the } \\
\text { wheelchair }\end{array}$} & 6 & 5.5 & 5.5 & 5 & 6 \\
\hline \begin{tabular}{|l|} 
Participant group B \\
\end{tabular} & & 4 & 4 & 3.5 & 4 & 4 \\
\hline $\begin{array}{l}\text { Participant group } \\
\text { A and B }\end{array}$ & & 5.5 & 5 & 5 & 5 & 6 \\
\hline
\end{tabular}

Subjective evaluation on the operation and using a wheelchair was conducted (Table 3). Each time a participant completes one trial, the caregiver (operator) gave a score of 7 levels ( 7 is the best, 4 is neutral, and 1 is the worst) for each operation process on "operating force required" and "ease of operation", while the evacuated (person in wheelchair) reported on "comfort level when using the wheelchair" and "sense of ease when using the wheelchair". The median value (median) of each score is shown in Table 3. Comparing between the median values of the scores of the two groups, the "operating force required" was given a score of 4 to 6 for each process. A score of 4 was given for "Mounting the wheelchair" and "Moving on the lower floor" which was found to be lower than the scores of other processes. "Ease of operation" was scored at 4 to 6 for each process. The score for "moving on the lower floor" was 4 , which was lower than the score for other processes. The score on "comfort level when using the wheelchair" and "sense of ease when using the wheelchair" for each process was 5 to 6 .

\section{B. Result of questionnaire survey with trial}

To the question of whether or not you feel it necessary to have an evacuation device that can be used to descend stairs for persons in wheelchairs, two persons answered "feel it strongly necessary", three answered "feel it necessary", and one answered "not feel it necessary". To the question of whether or not you want to introduce the machine into your facility, five respondents answered "want to introduce (including one who answered "want to introduce if easier to handle") and one for "not want to introduce so much". Opinions for improvement included reducing the weight of the equipment, making it easier to understand the handling procedure, and having voice guidance [7] for handling like AED. The results showed that 5 out of the 6 facility staff felt the need to introduce equipment that can evacuate persons in wheelchairs by descending the stairs. One person who was negative to the idea of adopting the equipment cited difficulties in handling as the reason.

\section{DISCUSSIONS}

\section{A. Discussion on test results and clarifying points to be improved}

We examined the results of the stairs descent experiment to find the cause of which "Mounting the wheelchair" accounted for $47.5 \%$ of the total processes. The video data of the experiment showed that it took a long time to unlock the section that supports the back frame of the developed machine with the top of the operator's foot pushed up during the process of mounting the wheelchair (Fig. 16). This was considered to be one of the common factors between the lower scores found in the "Mounting a wheelchair" process and in the opinion of requiring easier handling of the machine in the subjective evaluation results. In addition, about 30 times of use caused a failure in the hinge section with the spring in the lock falling out of position. We thus decided to improve the lock.

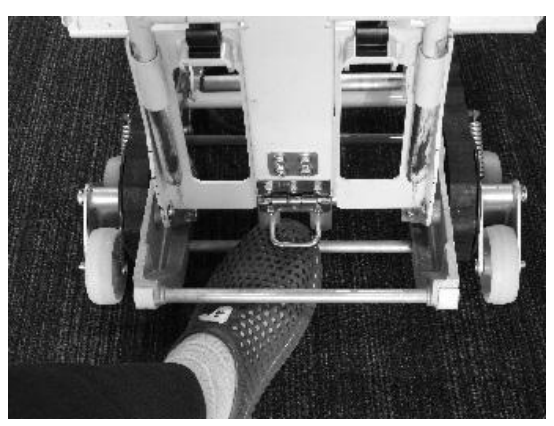

Fig. 16 Unlocking 


\section{B. Improvement of developed machine and verification of the effect}

The lock was improved in response to the results of the stair descent experiment and trial evaluation. The lock was changed to a configuration that can be released by pushing down with the sole of the foot without using a spring hinge (Fig. 17). At the same time, an impact resistance test was performed on the improved machine with a load weight of $115 \mathrm{~kg}$ by lowering from the stairs to the downstairs floor 500 times and we were able to confirm that there was no malfunction.

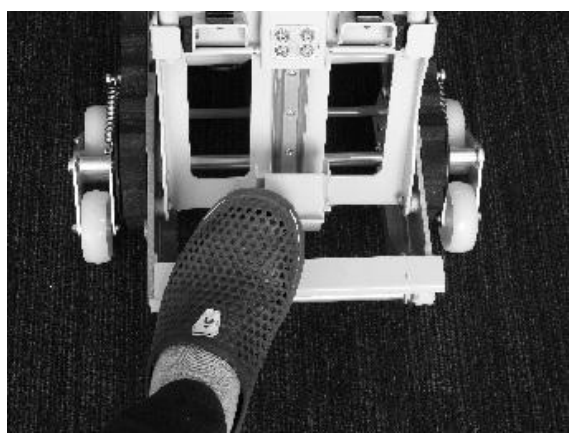

Fig. 17 Improved unlocking process

A stair descent experiment was conducted with the improved machine, and the operation process time was compared with those of the not-yet improved machine. The experimental conditions were the same as those before the improvement, and participated in by the participants of group B. The results showed the "Mounting the wheelchair" process time was reduced by an average of 9.88 seconds (Table 4). In addition, the participants gave the opinion that the process of mounting the wheelchair became easier than before the improvement. Changing the lock contributed to shortening the operation time, and improving the handling and robustness of the machine.

Table 4 Comparison of operation process time

\begin{tabular}{|c|c|c|c|c|c|c|c|}
\hline \multicolumn{2}{|c|}{ Number of process } & 1 & 2 & 3 & 4 & 5 & \\
\hline $\begin{array}{c}\text { Participant } \\
\text { group B }\end{array}$ & Operation & $\begin{array}{c}\text { Mounting } \\
\text { the } \\
\text { wheelchair }\end{array}$ & $\begin{array}{l}\text { Moving } \\
\text { on the } \\
\text { upper } \\
\text { floor }\end{array}$ & $\begin{array}{l}\text { Descend- } \\
\text { ing the } \\
\text { stairs }\end{array}$ & $\begin{array}{l}\text { Moving } \\
\text { on the } \\
\text { lower } \\
\text { floor }\end{array}$ & $\left|\begin{array}{c}\text { Removing } \\
\text { the } \\
\text { wheelchair }\end{array}\right|$ & Total \\
\hline \multirow{5}{*}{$\begin{array}{c}\text { Before } \\
\text { improvement }\end{array}$} & Average (s) & 30.84 & 6.68 & 15.75 & 3.35 & 16.77 & 73.40 \\
\hline & Minimum (s) & 22.70 & 3.80 & 12.00 & 2.03 & 11.87 & 65.37 \\
\hline & Maximum (s) & 35.93 & 12.47 & 20.17 & 4.63 & 20.13 & 87.77 \\
\hline & \begin{tabular}{|l} 
Standard \\
deviation (s)
\end{tabular} & 4.84 & 3.45 & 3.16 & 0.99 & 3.11 & 7.53 \\
\hline & $\begin{array}{l}\text { Coefficient of } \\
\text { variation }\end{array}$ & 0.16 & 0.52 & 0.20 & 0.30 & 0.19 & 0.10 \\
\hline \multirow{5}{*}{$\begin{array}{c}\text { After } \\
\text { improvement }\end{array}$} & Average (s) & 20.96 & 4.88 & 13.19 & 1.36 & 9.03 & 49.42 \\
\hline & Minimum (s) & 16.80 & 2.73 & 12.37 & 1.03 & 6.97 & 45.83 \\
\hline & Maximum (s) & 27.30 & 6.87 & 13.83 & 1.50 & 10.90 & 56.03 \\
\hline & \begin{tabular}{|l} 
Standard \\
deviation (s)
\end{tabular} & 3.61 & 1.85 & 0.60 & 0.18 & 1.60 & 4.42 \\
\hline & $\begin{array}{l}\text { Coefficient of } \\
\text { variation }\end{array}$ & 0.17 & 0.38 & 0.05 & 0.13 & 0.18 & 0.09 \\
\hline Difference & Average (s) & -9.88 & -1.80 & -2.56 & -1.99 & -7.74 & -23.98 \\
\hline
\end{tabular}

In addition, a comparison of the time of the entire operation process before and after the improvement showed that the average time decreased from 73.40 seconds before the improvement to 49.42 seconds after the improvement. The operation process time was reduced by an average of 23.98 seconds, and the operation process from wheelchair mounting to stair descent and wheelchair removing was carried out in under one minute. The participants, which were from group B (fire-fighting staff), might become more proficient at the operation of the developed machine by repeatedly performing trials in two experiments before and after the improvement and observing the trials of other participants. If elderly facilities' staff, who are prospective users of the machine, practice the operation in regular fire evacuation drills [8] and become proficient in handling the machine, the operation process time may be further shortened.

\section{SUMMARY}

An evacuation device that enables persons in wheelchairs to descend stairs was developed. A staircase descent experiment was conducted and the results showed that the total operation time was 92.18 seconds on average, which almost achieved the target time of 90 seconds. The result of a questionnaire survey showed that respondents had positive opinions on the necessity of equipment that can evacuate persons in wheelchairs by descending stairs and some said they need to introduce such equipment into their facilities. The lock of the developed machine was improved, which reduced the wheelchair mounting process time by an average of 9.88 seconds. The total operation time was 49.42 seconds on average, which made it possible for the evacuation time to be conducted in under one minute. Further improvements will be carried out leading to greater practical use [9].

In this study, the facilities targeted for evacuation were assumed to be elderly facilities, but in other facilities where there are wheelchair users on the upper floors, such as public facilities including hospitals and public halls, apartment buildings [10] and office buildings, where this study may also be applicable. Information on the needs for evacuation in such facilities will be collected and effective evacuation methods will be further studied.

\section{REFERENCES}

[1] Masami Shinozaki, Ai Sekizawa, Kyoichi Kobayashi, Katsunori Sasaki, "International Comparative Analysis on Regulatory Provisions and Codes of Fire Evacuation Safety for Physically Challenged People," Bulletin of Japan Association for Fire Science and Engineering, vol.66(2), 2016, pp.21-30.

[2] Sapporo Fire Bureau, "Report on the Mirai Tonden Fire and an Actua Fire Safety Survey of the Group Homes for the Elderly People with Dementia in Sapporo City," JOURNAL OF JAPAN ASSOCIATION FOR FIRE SCIENCE AND ENGINEERING, vol.60(5), 2010, pp.33-38.

[3] Tomoya Miyasaka, Keiko Kawashima, Mamiko Kamoshida, Katsuyuk Toide, Noriyuki Sugawara, Shinya Hashimoto, Atsushi Matoba, Kouhei Takatsuka, Kenji Edazawa and Masanori Kawai, “A development of evacuation vehicles for stairs that can descend while getting on wheelchair," Proceedings of JAFSE Annual Symposium 2018, 2018, pp.152-153.

[4] Tomoya Miyasaka, Yuji Tanaka, Keiko Kawashima, Yoshimi Tanahashi, Shiho Namba, Takahiro Tsukame, Hiroyuki Tamura, Nobuyuki Abe, Ken'ichi Takanashi, Sanae Matsushima, Daisuke Kozeki, Takayuki Saito, Ryo Tazawa, Jun Ito, Noriyuki Miyashita, “A Study on Evacuation Capability of Residents in Elderly Facilities," Proceedings of JAFSE Annual Symposium 2015, 2015, pp.44-47.

[5] Sanwa Ltd., "Kyaridan CD-8," http://www.sunwa-jp.co.jp/?page_id=35 
[6] Yoshinobu TAKAHASHI, "Japanese industrial stamdard of manual wheelchairs and powered wheel chairs." Bulletin of the Japanese Society of Prosthetic and Orthotic Education, Research and Development, vol.11(4), 1995, pp.281-287.

[7] Hideo Mitamura," Usefulness and problems of voice navigation system in automated external defibrillator (AED)," J Jpn Soc Intensive Care Med, vol.18(1), 2011, pp.20-22.

[8] Yukiko INOUE, Satoshi ISHII, Tatsuya NISHINO, “ACTUAL CONDITIONS AND PROBLEMS OF FIRE SAFETY IN THE GROUP LIVING FOR THE ELDERLY WITH DEMENTIA AND THE COMMUNITY BASED MULTI-CARE FACILITY," AIJ J. Technol. Des. vol.18(40), 2012, pp.1023-1028.

[9] Sanwa Ltd., "Chair CARRY DUN CCD 1," http://www.sunwa-jp.co.jp/?page_id=954

[10] Hiroko SAITO, "Influence and Issues on Condominium Management by the Great East Japan Earthquake," THE JAPANESE JOURNAL OF REAL ESTATE SCIENCES, vol.25(2), 2011, pp.126-135. 